\title{
РАЗДЕЛУІ. ЭКОНОМИКА
}

\author{
Denenberg Y.M., Surnina K.S. \\ Regional features of ensuring economic security of the budgetary sphere \\ Crimean Federal University \\ (Russia, Simferopol)
}

doi 10.18411/scc-09-2018-16

idsp 000001:scc-09-2018-16

\section{Annotation}

Today, theories of the multi-purpose management of the safe development of the economic systems of the regions in which the threats of the income gap, aggressive forms of mergers and acquisitions of property, the criminalization of economic activity, the problems of food security, the functioning of the transport and financial subsystems, and the like are of particular importance. In some regions, there has been accumulated some experience in various forms of organization of work of local administrations in the field of ensuring the economic security of the facility at various levels and scales, but a scientifically sound system of economic security, including in the budgetary sphere, with its inherent institutions and mechanisms for preventing new challenges and economic threats, especially at the regional level. The theoretical and methodological aspects of the construction and functioning of an integrated system of multi-purpose management of socio-economic complexes of regions that would be able to maintain the system properties of individual territories in the process of their dynamic and sustainable development have not been systematically studied.

Keywords: region, economic security, economic system.

In modern conditions, it is not necessary to talk about a balanced system for realizing the economic development of regions, because of the existence of a significant level of differentiation of their development, due to significant territorial, resource and administrative differences, so the definition of the concept of economic security of the region is a very urgent issue of our time.

Spatial-territorial parameters of the security of the territorial organization of the society generate the problem of economic security to the budgetary sphere at the regional level. The regional mechanism for ensuring economic security in the budgetary sphere is an element of the overall system of economic security of the state and reflects general patterns, criteria and indicators, but in such forms and with such peculiarities that are determined by the specifics of the region. Obviously, the general criteria and the economic security of the system elements of the budget sphere is invariant to the level of specificity remain relevant at the macro and micro levels mesas o-, separately in any region, regardless of their size, economic and geographic, industry, social and other features. At the same time, it is obvious that in states characterized by a significant differentiation in the levels of development and socioeconomic characteristics of individual regions, economic security in the budgetary sphere of each of them has features that must be taken into account in the management process.

The problems of regional development of economic security were studied in the works of such scientists as Dolmatov I.V., Abalkin L.I., Dolenko D.V., Dreyer O.K. and others. However, the regional mechanism for ensuring economic security in the budgetary sphere in modern science is considered very mediocre, which led to the urgency and objective necessity of further consideration of the issues of the functioning of the regional mechanism for ensuring economic security in the budgetary sphere. The aim of the article is to 
define especially her functioning of a regional mechanism to ensure economic security in the public sector.

To date, scientific developments in the field of economic security are based on the theory of general scientific categories and definitions of economic security of the territory as a regional socio-economic system. The term economic security at the regional level is so As well as national security is a complex and multidimensional phenomenon, which includes a wide variety of security.

In modern scientific literature, the concept of the region is interpreted contradictorily $\mathrm{B}$ is ambiguous, therefore, for a more precise understanding, we will consider different approaches to discovering the essence of the concept of the region. The region should be viewed in at least two aspects: broad and narrow. In a broad sense, the region is a group of states located in the same geographical region and related by a number of factors: geopolitics, military strategy, security, defense, economic integration and others.

"In a narrower understanding, the region is a part of the state that is separated from other regions by a combination of natural or persistent economic, geographical and other features that are often combined with the characteristics of the national composition of the population " [1, p. 16 ]. "In order to avoid the ambiguity of the concept, it is necessary to call the territorial units of the subnational level regional regions, it is expedient to use the concept of "macroregion" for regions of supranational level, which will emphasize another character of such region" [2, p. 46].

In general, science in the region means a certain territory, which is a component of the territorial-economic and national-cultural complex, which can be delimited by signs of intensity, diversity and interconnectedness of phenomena that are expressed in the form of specific homogeneity of geographic, natural, economic, socio-historical, national cultural conditions, which are the basis for allocating this territory. However, each scientific discipline gives priority to this or that region-forming feature, therefore under the region in such cases sometimes different objects are meant.

The economic potential of the region is the basis of its development. The region is an integral element of the economic system, within which presents the main indicators of socioeconomic structure of production, for which characterized by the presence of natural $\mathrm{x}$ and resource factors, processes management is carried out by regional authorities. The region is one of the key objects of organizational-economic and political-legal relations aimed at the organization of a regional economy, the formation of favorable living conditions and the satisfaction of the needs of the population, taking into account the specifics of its development, but the disproportionate socio-economic development of the regions is steadily growing.

The region as a term includes a number of fundamental characteristics: a common territory, a certain population, a common history, natural conditions, and the rest depend on the tasks that the researcher decides. Thus, in the economic literature, two concepts of the region most often appear, with the equality sign often being drawn between the concept of "region" and "district".

In the theory of public administration, a formal legal interpretation of the region as a subject of a federation or another subnational unit whose rights and obligations are indicated by the constitution or other laws is given.

Thus, proceeding from the above approaches to the region's consideration, it can be argued that regions in the Russian Federation can be either a republic or separate regions or their associations, that is, territories that have a socio-economic and ethno-cultural community in conjunction with historical and cultural traditions.

The need for additional more in-depth and detailed analysis of the regional aspects of economic security due to the fact that the social and economic processes, the structure of production and consumption are becoming more pronounced the first regional first character, which is associated both with the uneven distribution of natural resources, regional 
differences in climatic conditions, the existing system of population settlement, the traditions of the economic system, and the processes of globalization and integration. The use of natural resources, protection of the natural environment, and socio-economic development always correspond to a certain territory. Under these conditions, there is an objective change in the role of regional security in the development of society.

The insufficient elaboration of many aspects of economic security at all its levels in relation to the transformation period, the theoretical and practical importance of the problem of overcoming and preventing crisis situations in the economies of the regions for their effective functioning in the integrated economic space within a single state stipulate new approaches to the economic security of the national economy and the region's economy.

Economic security of the region determines the ability of the regional economy to consistently support the consistent implementation of national and state interests, the stable and reliable capacity of economic entities, normal living conditions of the population. The region as an economic system reflects a part of the territory of the country within which a system of interaction between economic entities functions and develops. In a market economy and with all the diversity of forms of ownership, the region as an economic system can be considered as a relatively independent object of economic regulation. Traditionally, the internal structure of the region's economic security, as a rule, is displayed through three important blocks:

1) economic independence, which is relative due to the economic and political dependence of the region on the center and the interconnectedness of various regional economies (in such conditions, the economic independence of the region indicates the ability of regional authorities to control regional resources, achieving this level of production, efficiency and quality ensures its competitiveness and allows, under their equal conditions, to participate in interregional and international trade, cooperative ties and the exchange of scientific and technological achievements);

2) stability and sustainability of the regional economy (involving the protection of property of all forms, creating reliable guarantees and favorable conditions for entrepreneurship, deterring factors capable of destabilizing the situation, such as combating criminal structures in the economy, preventing serious disruptions in the distribution of incomes that threaten social upheaval);

3) ability to self-development and progress (creating a favorable climate for investment and innovation, continuous modernization and expansion of production, raising the professional level of workers, etc.).

Economic security of the budgetary sphere at the regional level has many aspects and levels, starting with the identification of conditions and criteria for security, taking into account the specific geographical dimensions of the regions. The subject of consideration in this case is economic security in the budgetary sphere of the regions within the borders of certain countries and mainly economic security in the budgetary sphere of the regions of the Russian Federation.

Economic security in the budgetary sphere at the regional level has interrelated qualitative quantitative parameters. Qualitative safety parameters are reflected in its structure. " The structure of economic security of the budgetary sphere at the regional level is determined by the dependencies of regional economic reproduction on the external natural and social environment and is embodied in a system of blocks and elements that always interact with each other and with other elements of social security - military-political, legal, ideological, demographic and other " [3, p.34 ]. The social reasons for the economic security of the budgetary sphere at the regional level can also be structured along hierarchical levels of social organization: firstly, the reasons for the general social and general state level that affect the security of the region; secondly, these are the causes that reflect the interaction of the general social and regional processes, and thirdly, these are internal regional factors of economic security. 
Economic security in the budgetary sphere at the regional level has its own peculiarities in the formation and functioning of regional systems for ensuring economic security, that is, those institutions and mechanisms that are recognized to protect the economic interests and property of the individual, the population, and economic entities of the region.

In the wake of regional institutions and structures for ensuring economic security, the budgetary sphere includes not only combating violations of tax legislation, detection, warning and termination of violations in the financial and financial legislation, but also to ensure the retention of the requirements of the law, the regulation of relations in the field of entrepreneurial and other economic activities, as well as property relations.

At present, the regions of the Russian Federation have formed as integral economic systems and have their own peculiarities and economic policy, independence in choosing an economic development strategy, and the sphere of ensuring economic security in the budgetary sphere in each region of the country also has its own specifics.

"The economic interests of the region are, first of all, the effective use of productive potential and natural resources while ensuring favorable living conditions and social conditions of the population" [4, p.2]. Based on the interests of the region, a regional strategy for ensuring economic security must be formed.

However, the definitions that treat economic security in the budgetary sphere at the regional level are practically non-existent, therefore, in order to understand the essence of this concept, we will consider how the economic security of the region is interpreted. There is no doubt that in the provision of economic security in the budgetary sphere at the regional level, institutions and mechanisms for the exchange of information resources and information protection play a special role.

Economic security is a combination of conditions and factors that characterize the current state of the economy, stability, stability and progressiveness of its development. "Economic security is traditionally regarded as the most important qualitative characteristic of the economic system, which determines its ability to maintain normal living conditions of the population, sustainable provision of resources with the development of the national economy, the consistent realization of national and state interests, and also as a system of measures to protect the economic space of the region from external and internal threats that impede the effective functioning of constituent regions tional economy: institutional infrastructure, the private sphere of production, transportation facilities and communications, science and research institutions, social support systems "[5, p.15].

"Vaikhanov H.H. notion of" national security at the regional level, "formulated in such a way -" is an integral organic broader phenomenon ", which is fixed at the level of the region of a State, including the different types of security, and is the state of protection of national interests from internal and external threats at the level of an individual, society, and, in fact, the region and the entire state, to which the region belongs " [6, p.175].

The object of economic security of the region is the regional economy as a system of interaction between the industrial, social and natural-ecological spheres. The subjects of economic security in the region are the bodies of state power, the specificity of which lies in the fact that the original government implements on its territory not only nation-wide, but also its own interests. The powers of the government during the political situation should be the continuation of their functional duties. Strategic management of the processes of territorial development determines the objective need of the regions to have their own concept of national security.

Thus, the formation of a clear theoretical basis, which can be created on the basis of the theory of economic interests, allows the most complete and profound disclosure of the essence of economic phenomena and processes, should become the basis for solving problems in providing conditions for improving the level of economic security. Formation of a holistic concept of economic security of the national economy is impossible without considering 
regions as independent economic entities, carriers of economic interests both within the country and in the construction of relations of international cooperation. The economic security of the region directly depends on the regional economy and the economic potential of a particular region.

Economic security in the budgetary sphere at the regional level is a combination of the current state of the conditions and factors that characterize the stability, stability of the development of the economic territory, a certain independence and integration with the economy of the country, which is expressed in such manifestations: the ability to pursue its own budgetary policy within the country, opportunities to address socially unsafe situations in areas associated with local economic threats, possibility to stably maintain compliance with existing public services in the territory in accordance with the prudential international practices that would preserve or renew a decent standard of living.

$$
* * *
$$

1. Arsentieva I.I. Russian regions in the national security system. - M., 2008. - p.16.

2. Turovsky R.F. Center and Regions: Problems of Political Relations. - M., 2007.- p. 46.

3. Yeletsky N.D. Economic security of the region in the system of social security of the country / / South Russian Review. - 2008. - №50. - p.34.

4. Dolmatov I.V. Regional aspects of ensuring economic security // Audit and financial analysis // 2007. №1. - from. 2.

5. Bykov V.P, Dembovskaya OA, Lebedko EM Economic security of regions and overcoming of threats in modern conditions (BGITA, Bryansk, Russia) 2006.

6. Vayhanov H.H. National security of russia at the regional level / Otv. Ed. I.P. Add . - Rostov-on-Don: Publishing house SKNTS VS SFU, 2010. - 175s.

\section{Kaldybayev Y. K., Orazalyev B.M. Economic risks in Kazakhstan}

Almaty technological university (Kazakhstan, Almaty)

doi 10.18411/scc-09-2018-17

idsp 000001:scc-09-2018-17

\section{Abstract}

The paper analyses the impact ofhigh credit risk in Kazakhstan.

Standard \& Poor's Ratings Services classifies the banking sector of Kazakhstan group '8' under its Banking Industry Country Risk Assessment (BICRA). Economic risks in Kazakhstan remain very high in a global context.

S\&P views of extremely high credit risk in Kazakhstan takes into account the banks' history of aggressive underwriting standards and the country's weak payment culture and rule of law.

During the 2004-2007 real estate boom, banks' loan portfolios expanded by more than $50 \%$ annually. The global economic crisis put an abrupt end to years of aggressive lending that was largely financed by wholesale borrowing. The burst of the property and credit-fuelled bubble severely affected banks, leading to some defaults and bailouts. Economic restructuring since 2009 has borne some fruit, but the economy can remains vulnerable to further losses while banks work through their substantial backlog of problem assets.

The aim of this paper - is showed economic risks in Kazakhstan. The author also aim at identifying current banking industry issues.

Keywords: Bank, credit risk, Kazakhstan, credit, economy 